\title{
Kekuatan dan Kesulitan Remaja Disabilitas di Yayasan Pendidikan Anak Cacat (YPAC) Jakarta dan Surakarta
}

\author{
Tri Riana Lestari ${ }^{1}$, Atikah Adyas ${ }^{2}$, Elsye Rachmawaty ${ }^{3}$, Yopi Harwinanda Ardesa ${ }^{4}$, \\ Ester Syeftty Pasaribu ${ }^{5}$ \\ 1,2,5 Jurusan Ortotik Prostetik, Politeknik Kesehatan Kemenkes Jakarta I, Indonesia \\ ${ }^{3}$ Jurusan Keperawatan, Politeknik Kesehatan Kemenkes Jakarta I, Indonesia \\ ${ }^{4}$ Jurusan Ortotik Porstetik, Politeknik Kesehatan Kemenkes Surakarta, Indonesia \\ Email: tririanalestari@yahoo.co.id
}

\begin{abstract}
Strength and Weakness in Adolescence with Disability at Jakarta and Surakarta Education Foundation of Disability Children (YPAC). Children with disability face the barriers due to their incapacity and various obstacles from their society. How to cope with the barriers that came from themselves due to physical imperfection, emotional instability, and obstacles from the environment will affect to their mental health. The Medical assessment to find out the strengths and difficulties of teenagers are intended to take early intervention and an effort to improve the mental and personality development of teenagers with disabilities. This research was conducted to find out about the description of disabled adolescence's characteristic profile on strength and weakness that related to adolescence mentality at school for the disabled. The cross-sectional study was conducted at YPAC Jakarta and Surakarta in the period of June-October 2017. This research was conducted with 100 respondents from YPAC, 20 people from Jakarta and 80 people from Surakarta. The qualification of the respondents were adolescences with a range of age 11-18 years old, adolescents with limb and or vision disability that capable to communicate, and agree to be respondents. The study results showed that there were $27 \%$ children whose 11-12 years old, $24 \%$ whose 13-14 years old, $28 \%$ whose $15-16$ years old, $21 \%$ whose 17-18 years old. The respondents were males $58 \%$ and females $42 \%$. This research has successfully explained that Most of the difficulty level of adolescents with disabilities found in YPAC Jakarta and Surakarta were normal level $(79 \%)$, and most of the level of strength were also normal level (89\%). Suggestions for all parties related to disability adolescents as an effort to maintain mental health and not late to intervene.
\end{abstract}

Keywords: Difficulty, Disability, Special school, Strength

\begin{abstract}
Abstrak: Kekuatan dan Kesulitan Remaja Disabilitas di Yayasan Pendidikan Anak Cacat (YPAC) Jakarta dan YPAC Surakarta. Anak-anak penyandang disabilitas menghadapi tantangan-tantangan lain akibat ketidakmampuan mereka dan berbagai rintangan yang dihadirkan oleh masyarakat mereka sendiri. Cara merespon banyaknya tantangan dari dalam diri remaja disabilitas karena ketidaksempurnaan fisik maupun ketidakstabilan emosi yang dimiliki serta rintangan yang muncul dari lingkungan akan memengaruhi kesehatan mental remaja disabilitas. Pemeriksaan kesehatan mental dengan mengetahui kekuatan dan kesulitan pada remaja ditujukan untuk mengambil tindakan intervensi dini sebagai upaya preventif maupun upaya penanganan pada perkembangan mental dan kepribadian remaja disabilitas. Penelitian ini bertujuan mengetahui profil karateristik kekuatan dan kesulitan remaja disabilitas yang berkaitan dengan kondisi kesehatan mental remaja di dalam sekolah disabilitas. Studi cross-sectional ini diadakan di YPAC Jakarta dan YPAC Surakarta pada rentang waktu Juni-Oktober 2017. Penelitian ini melibatkan 100 responden yang terdistribusi dari responden remaja disabilitas YPAC Jakarta sebanyak 20 orang, dan YPAC Surakarta sebanyak 80 orang. Kualifikasi responden ialah anak dengan rentang usia 1118 tahun, remaja tuna daksa dan atau tuna netra yang memiliki kemampuan untuk berkomunikasi, dan bersedia menjadi responden. Anak dengan usia 11-12 tahun sebanyak 27\%, usia 13-14 tahun sebanyak 24\%, 15-16 tahun sebanyak 28\%, dan usia 17-18 tahun sebanyak 21\%. Responden lakilaki $58 \%$, dan perempuan $42 \%$. Penelitian ini berhasil memaparkan bahwa tingkat kesulitan pada remaja dengan disabilitas yang ditemukan di YPAC Jakarta dan Surakarta yang terbanyak adalah kesulitan remaja dengan tingkat normal sebanyak 79\%, serta tingkat kekuatan remaja disabilitas normal sebesar $89 \%$. Saran kepada seluruh pihak terkait dengan remaja disabilitas sebagai upaya untuk menjaga kesehatan mental dan tidak terlambat melakukan intervensi.
\end{abstract}

Kata kunci: Kesulitan, Disabilitas, Sekolah Luar Biasa, Kekuatan 
Anak dengan disabilitas di Indonesia menempati posisi yang cukup krusial. Stigma masyarakat terhadap anak disabilitas terkadang masih kuat karena rendahnya pengetahuan dan faktor sosial budaya. Rendahnya pengetahuan dan kepekaan masyarakat sekitar tercermin dari bagaimana aspek-aspek dukungan sosial seperti dukungan instrumental yang terwujud dalam pemenuhan keperluan fisik anak seperti makan, pakaian, tempat tinggal dan pemeliharaan kesehatan, juga penyediaan keuangan untuk anak dengan disabilitas dipenuhi (Halfon, Houtrou, 2012). Bagaimana mereka merasa diterima dengan kekurangan yang mereka miliki, berapa banyak teman yang mereka miliki, atau kualitas partisipasi dan dilibatkannya mereka dalam pengambilan keputusan adalah faktor primer yang mempengaruhi kehidupan mereka (Belaney, Smith, 2012). Dalam hasil penelitian WHO, didapatkan bahwa 1 dari 5 anak yang berusia kurang dari 16 tahun mengalami masalah mental emosional. Anak yang berusia 4-15 tahun yang mengalami mental emosional sebanyak 104 dari 1000 anak. Angka kejadian tersebut makin tinggi pada kelompok usia di atas 15 tahun, yaitu 140 dari 1000 anak

Dukungan sosial adalah aspek yang berpengaruh signifikan bagi anak dengan kesehatan mental remaja disabilitas. Sebagai contoh, strategi pengajaran yang secara langsung mempromosikan kerjasama antara siswa dapat meningkatkan pengalaman sosial di dalam kelas (Aron, Loprest, 2012). Pemeriksaan kesehatan mental merupakan kegiatan untuk menentukan secara dini adanya masalah masalah emosional agar dapat di ketahui dan segera dilakukan tindakan intervensi. Berdasarkan hasil penelitian yang dilakukan pada 578 siswa Sekolah Menengah Pertama (SMP) di kota Semarang tahun 2009, prevalensi masalah mental emosional sebesar 9,1\% (Hartanto, 2011). Bila masalah mental emosional terlambat diketahui, maka intervensinya akan lebih sulit dan hal ini akan berpengaruh pada perkembangan mental dan kepribadian remaja, khususnya jika itu terjadi pada disabilitas. Pemeriksaan kesehatan mental remaja disabilitas dilakukan untuk mengetahui karakteristik kesehatannya.

\section{METODE}

Penelitian ini dilakukan di Sekolah Luar Biasa (SLB) Yayasan Pendidikan Anak Cacat (YPAC) Jakarta dan Surakarta. Populasi pada penelitian ini adalah remaja dengan disabilitas. Sampel kasus penelitian ditentukan dengan kriteria Remaja (10-18 tahun), remaja tuna daksa atau tuna netra atau keduanya, seta bersedia menjadi responden. Penelitian ini menggunakan metodologi cross-sectional study. Pengumpulan data dilakukan dengan skrining pemeriksaan kesehatan mental menggunakan kuesioner kekuatan dan kesulitan pada anak/remaja atau Strength and Difficulties Questionnaire (SDQ). Skor kesulitan di sini ditentukan dari beberapa tolak ukur yang meliputi gejala emosional, masalah perilaku, hiperaktivitas, dan masalah teman sebaya. Kemudian, jumlah skor dari keempat faktor tersebut dijumlahkan dan di kalkulasikan untuk mengetahui tingkat kesulitan yang dimiliki remaja disabilitas dengan interval tingkat normal dengan skor 0-15, tingkat borderline dengan skor 16-19, serta tingkat abnormal dengan skor 20-40. Ada 100 remaja disabilitas yang menjadi responden studi penelitian ini; 80 remaja merupakan siswa Sekolah Luar Biasa YPAC Surakarta dan 20 remaja merupakan siswa Sekolah Luar Biasa YPAC Jakarta.

Faktor gejala emosional yang dimaksudkan dalam kuesioner meliputi permasalahan seperti apakah remaja disabilitas sering mengeluh sakit pada badan (seperti sakit kepala, perut, dll), memiliki banyak kekhawatiran, sering tidak bahagia, menangis, gugup atau mudah hilang percaya diri, dan mudah takut. Selanjutnya, faktor masalah perilaku meliputi apakah remaja disabilitas sering marah meledak-ledak, umumnya berperilaku tidak baik, tidak melakukan apa yang diminta orang dewasa, sering berkelahi, sering berbohong, sifat curang, dan mencuri. Faktor hiperaktivitas mencakup perilaku remaja disabilitas yang gelisah, terlalu aktif, tidak dapat diam lama lama, terus bergerak dengan resah, perhatian mudah teralih, konsentrasi buyar, tidak berpikir sebelum bertindak, dan tidak mampu menyelesaikan tugas sampai selesai.

Faktor keempat, yaitu faktor masalah teman sebaya. Pertanyaan dalam kuesioner yang mengukur tingkat faktor ini ialah apakah remaja disabilitas cenderung menyendiri, lebih senang main sendiri, tidak punya satu teman baik, tidak disukai anak-anak atau teman lain, diganggu atau digertak oleh anak lain, dan apakah remaja disabilitas lebih senang bergaul dengan orang dewasa dari pada anak-anak. Selanjutnya, skor kekuatan hanya diukur dengan satu faktor, yaitu perilaku prososial remaja disabilitas. Faktor ini mencakup aspek-aspek seperti apakah remaja mampu mempertimbangkan perasaan orang lain, bersedia dengan anak lain, suka menolong, bersikap baik pada anak yang lebih muda, dan 
sering menawarkan diri membantu orang lain.

\section{HASIL}

Tabel 1. Distribusi Frekuensi
Disabilitas berdasarkan Usia

\begin{tabular}{lrr}
\hline \multicolumn{1}{c}{ Usia } & \multicolumn{1}{c}{ Frek } & \multicolumn{1}{c}{$\%$} \\
\hline 11 sd 12 tahun & 27 & 27.0 \\
13 sd 14 tahun & 24 & 24.0 \\
15 sd 16 tahun & 28 & 28.0 \\
17 sd 18 tahun & 21 & 21.0 \\
Total & 100 & 100 \\
\hline
\end{tabular}

\begin{tabular}{crr}
$\begin{array}{c}\text { Tabel 2. Distribusi } \\
\text { Disabilitas } \\
\text { Kelamin }\end{array}$ & $\begin{array}{l}\text { Frekuensi } \\
\text { berdasarkan }\end{array}$ & $\begin{array}{r}\text { Remaja } \\
\text { Jenis }\end{array}$ \\
\hline \multicolumn{1}{|c}{ Jenis Kelamin } & Frek & $\%$ \\
\hline Laki-laki & 58 & 58.0 \\
Perempuan & 42 & 42.0 \\
Total & 100 & 100.0 \\
\hline
\end{tabular}

Tabel 3. Distribusi
\begin{tabular}{lrr} 
Disabilitas berdasarkan & \multicolumn{2}{c}{ Frekuensi } \\
Kesulitan & Frek & \multicolumn{1}{c}{ \% } \\
\hline Normal & 79 & 79.0 \\
Borderline & 18 & 18.0 \\
Abnormal & 3 & 3.0 \\
Total & 100 & 100,0 \\
\hline
\end{tabular}

Tabel 4. Distribusi
\begin{tabular}{ccc}
\multicolumn{2}{c}{ Disabilitas berdasarkan } & \multicolumn{2}{c}{ Frekuensi } & Remaja \\
\cline { 2 - 3 } \multicolumn{1}{c}{ Kekuatan } & Frek & $\%$ \\
\hline Normal & 89 & 89.0 \\
Borderline & 8 & 8.0 \\
Abnormal & 3 & 3.0 \\
Total & 100 & 100,0 \\
\hline
\end{tabular}

Interval usia remaja ialah 11-18 tahun. Remaja disabilitas terbanyak berada pada usia 15-16 tahun sebanyak 28 orang (28\%), selanjutnya di usia 11-12 tahun sejumlah 27 orang $(27 \%)$, kemudian diikuti oleh remaja dengan usia 13-14 tahun sebanyak 24 orang (24\%), serta usia 17-18 tahun yaitu 21 orang (21\%) (tabel 1). Remaja berjenis kelamin lakilaki mendominasi dengan jumlah persentase $58 \%$, atau sebanyak 58 orang, sedangkan responden remaja disabilitas perempuan berjumlah 42 orang dengan presentase $42 \%$ (tabel 2 ).

Berdasarkan kalkulasi data penelitian, berkaitan dengan hasil kuesioner Strength and Difficulties Quessionare (SDQ) ditemukan hasil tingkat kesulitan dan kekuatan dari remaja disabilitas di Sekolah Luar Biasa (SLB) YPAC Surakarta dan SLB YPAC Jakarta. Tingkat kesulitan yang dimiliki remaja disabilitas YPAC
Surakarta dan Jakarta ialah di tingkat Normal sebanyak 79 (79\%), tingkat borderline sebesar 18 (18\%), dan tingkat Abnormal sebanyak 3 anak (3\%) (tabel 3 ). Selanjutnya, tingkat kekuatan remaja disabilitas SLB YPAC Surakarta dan Jakarta berupa 89 anak di tingkat normal (89\%), 8 anak di tingkat borderline (8\%), serta di tingkat abnormal sebanyak 3 anak (3\%) (tabel 4).

\section{PEMBAHASAN}

Masa remaja adalah masa transisi dari anak menuju dewasa dan merupakan masa yang kritis dan penuh gejolak. Di masa ini terjadi perubahan biologis, psikologis, dan perubahan sosial. Kesenjangan antara perkembangan fisik, psikologi, dan sosial yang berbeda pada remaja dapat memicu terjadinya masalah mental emosional (Damayanti, 2011). Apabila remaja dapat memperoleh peran dalam masyarakat, maka dia akan mencapai sense of identity, menemukan identitas diri. Sebaliknya, apabila remaja tidak dapat menyelesaikan krisis identitasnya dengan baik, maka dia akan merasakan sense of confusion atau identity diffusion, yaitu suatu istilah digunakan untuk menggambarkan ketidakmampuan dalam memperoleh peran dan menemukan diri (Marheni, 2004). Hal ini tentu juga berlaku pada remaja disabilitas.

Perlu suatu upaya dan pemahaman khusus yang lebih mendalam guna membantu para remaja disabilitas dalam menemukan karakter mereka dan mencapai kesehatan mental yang baik dan tidak mengalami kecemasan. Akan tetapi, dalam kondisi yang tepat, kecemasan ini mendorong remaja untuk lebih bertanggung jawab, hati-hati, dan menjaga tingkah lakunya agar sesuai dengan norma yang berlaku. Remaja dapat bertingkah laku normal sesuai dengan harapan masyarakat (Dinas Kesehatan Sulsel, 2011).

Hal ini dapat dilihat dari ciri emosi remaja yang mudah mengalami depresi (sedih dan putus asa), kemudian melawan, memberontak. Selain itu remaja juga semangat untuk ingin tahu, agresif, mudah terangsang, dan mempunyai loyalitas tinggi kalau sudah menyukai sesuatu atau seseorang (Sarwono, 2003). Kasus yang sering terjadi ialah di nomor duakannya anak disabilitas, lewat salah satu cara, yaitu dengan tidak disekolahkan. Dapat disimpulkan bahwa definisi inklusi sosial anak-anak dapat mencakup tidak adanya penindasan, membuat rekan atau teman mereka menyadari kecacatan mereka, dan 
nilai yang mendorong penerimaan dan dukungan rekan (Currie, Kahn, 2012).

Sekolah Luar Biasa dibangun berdasarkan Undang-Undang Republik Indonesia Nomor 20 tahun 2003 tentang Sistem Pendidikan Nasional sebagai sarana pemenuhan hak anak dengan cacat mental dan atau fisik dalam mendapatkan pendidikan. Maka dari itu, Sekolah Luar Biasa diharapkan menjadi sarana yang tepat sasaran dalam perannya sebagai penyedia dukungan sosial yang menjadi preferensi terpenting dalam tingkat kesehatan mental remaja disabilitas. Orang tua diharapkan mampu mendapatkan tempat yang sesuai dalam mewadahi kebutuhan putra-putri mereka yang berkebutuhan khusus. Orang tua dengan putra-putri berkebutuhan khusus, mendapatkan tuntutan emosional yang lebih (Pelentsov, Lemuel J., Laws, Thomas A. 2015). Tingkat kesulitan yang dimiliki remaja disabilitas di SLB YPAC Surakarta dan Jakarta masih didominasi pada tingkat Normal. Sebanyak 79 remaja (79\%) memiliki tingkat kesulitan yang normal dalam gejala emosional, masalah perilaku, hiperaktivitas, dan masalah teman sebaya. Hal ini mengindikasikan kesehatan mental remaja di Sekolah Luar Biasa YPAC Surakarta dan Jakarta mayoritas berada pada tingkat kesehatan mental yang baik. Sebanyak 18 remaja (18\%) memiliki tingkat gejala emosional, masalah perilaku, hiperaktivitas, dan masalah teman sebaya yang dihadapi merupakan kesulitan dengan skala borderline, sehingga memiliki kesehatan mental yang kurang baik. Sedangkan 3 remaja (3\%) berada pada kondisi abnormal, sehingga mengindikasikan kesehatan mental yang di bawahbatas normal dan borderline.

Ditinjau dari karateristik kekuatan (tabel 4), sejumlah 89 remaja (89\%) memiliki kesehatan mental yang bagus, ini diindikasikan dari tingkat kekuatan yang berada pada skala normal. Maka, remaja disabilitas mampu mempertimbangkan perasaan orang lain, bersedia dengan anak lain, suka menolong, bersikap baik pada anak yang lebih muda, dan sering menawarkan diri membantu orang lain. Pada tingkat kekuatan borderline, sebanyak 8 remaja (8\%) memiliki kesehatan mental yang kurang baik. Selanjutnya, di posisi abnormal terdapat 3 remaja (3\%) dengan kemampuan mempertimbangkan perasaan orang lain, bersedia dengan anak lain, suka menolong, bersikap baik pada anak yang lebih muda, dan sering menawarkan diri membantu orang lain yang kurang.

\section{SIMPULAN}

Melalui hasil penelitian ini, karateristik kekuatan dan kesulitan remaja disabilitas yang berkaitan dengan kondisi kesehatan mental remaja Sekolah Luar Biasa YPAC Surakarta dan Jakarta menunjukkan kesulitan remaja dengan tingkat normal sebanyak $79 \%$, serta tingkat kekuatan remaja disabilitas normal sebesar $89 \%$.

\section{SARAN}

Kesehatan mental adalah aspek penting yang mendukung kesehatan jasmani seorang remaja, tidak terkecuali remaja disabilitas. Seluruh pihak yang terkait dengan remaja disabilitas diharapkan terus menyokong tumbuh kembang remaja disabilitas sebagai upaya untuk menjaga kesehatan mental remaja disabilitas dan tidak melakukan intervensi yang terlambat.

\section{DAFTAR PUSTAKA}

Aron, Laudan \& Loprest, Pamela. 2012. Disability and The Education System. Journal The Future of Children, Vol. 41. https://www.zapmeta.ws/ws?q=disability\% 20 journal\&asid=ws_gc_b7_5\&mt=b\&nw= g\&de=c\&ap=101. (Diakses pada 5 Mei 2017).

Belaney, Liam., \& Smith, James P. 2012. Childhood Health: Trends \& Consuquences over The Life Course. Journal The Future of Children, Vol.1. Princetoon-Brookings.

Currie, Janet \& Kahn, Robert. 2012. Children with Disabilities: Introducing The Issue. The Future of Children, vol. 41.

https://www.zapmeta.ws/ws?q=disability\% 20journal\&asid=ws_gc_b7 $5 \& \mathrm{mt}=\mathrm{b} \& \mathrm{nw}=$ g\&de $=$ c $\& a p=101$, (Diakses pada 5 Mei 2017).

Damayanti M. 2011. Masalah Mental Emosional pada Remaja: Deteksi dan Intervensi. Sari Pediatri, Volume 13 (Suppl 1) Juni 2011: Jakarta. hal.45-51 2.

Dinas Kesehatan Sulawesi Selatan. 2011. Profil Kesehatan Propinsi Sulawesi Selatan. Sulawesi Selatan.

Halfon, Neal., \&Houtrou, Amy \& Larson, Kandyce \& Newackeck, Paul W. 2012. The changing Landscape of Disability in Childhood. The Future of Children, 
Vol.41. https://www.zapmeta.ws/ws?q=disability\% 20journal\&asid=ws_gc_b7_5\&mt=b\&nw= g\&de $=$ c $\& a p=101$ (Diakses pada 8 Oktober 2017).

Hartanto F, Selina H. 2011. Prevalensi Masalah Mental Emosional pada Remaja di Kota Semarang dengan Menggunakan Kuesioner Kekuatan dan Kesulitan (SD). Paediatrica Indonesiana, Vol.51 (Suppl 4), hal. 30.

Marheni A. 2004. Perkembangan Psikososial dan Kepribadian Remaja dalam Buku Ajar Tumbuh Kembang Remaja dan
Permasalahannya. Jakarta: CV.Sagung Seto.

Pelentsov, Lemuel J., Laws, Thomas A. 2015. The supportive care needs of parents caring for a child with a rare disease : A scoping review. Disability and Health Journal, Vol. 8. Pp 36-42.

Pemerintah Republik Indonesia. 2003. UndangUndang Republik Indonesia Nomor 20 tahun 2003 tentang Sistem Pendidikan Nasional. Jakarta: Pemerintah Republik Indonesia.

Sarwono WS. 2003. Psikologi Remaja. Jakarta: PT. Raja Grafindo Persada. 